\title{
Education across the life-course and hypertension in adults from Southern Brazil
}

\author{
Educação no ciclo vital e hipertensão em adultos do Sul do Brasil
}

Waleska Nishida (https://orcid.org/0000-0002-4937-5124) ${ }^{1}$

Anna Ziersch (https://orcid.org/0000-0001-6600-2568) ${ }^{2}$

Carla Zanelatto (https://orcid.org/0000-0001-8541-9828) ${ }^{1}$

Kátia Jakovljevic Pudla Wagner (https://orcid.org/0000-0002-3649-3121) ${ }^{1}$

Antonio Fernando Boing (https://orcid.org/0000-0001-9331-1550) ${ }^{1}$

João Luiz Dornelles Bastos (https://orcid.org/0000-0002-1816-0745) ${ }^{1}$

\footnotetext{
${ }^{1}$ Programa de PósGraduação em Saúde Pública, Universidade Federal de Santa Catarina. R. Eng. Agronômico Andrei Cristian Ferreira s/n, Trindade. 88040-900 Florianópolis SC Brasil. waleska.nis@gmail.com ${ }^{2}$ Southgate Institute for Health, Society and Equity, Flinders University. Adelaide Austrália.
}

\begin{abstract}
The present study examines the association between life-course socioeconomic position (SEP) and hypertension (SAH), focusing on the health impacts of childhood SEP (SEPc), adult SEP (SEPa), as well as SEP mobility. Data from the Brazilian EpiFloripa Cohort Study $(n=1,720$; $56 \%$ women; $55 \%<=30$ years) were analyzed. SAH was determined by the average of two measures of systolic and diastolic blood pressure, previous medical diagnosis or use of anti-hypertensive medication ( $43 \%$ of the sample was hypertensive). The main independent variables were: SEPa - participants' level of education; SEPc parental educational attainment; and SEP mobility - the socio-economic trajectories from SEPc to SEPa. Five logistic regressions models were adjusted for sex, age or income, and were compared among each other. High SEPa was associated with a $37 \%$ reduction in the odds of SAH compared to low SEPa. High SEP over the life course was associated with 34-37\% lower odds of SAH compared to persistent low SEP. Mobility models explained more of the outcome variance than the sensitive period model. The results reinforce the importance of education in the risk of $S A H$ and the relevance of a socioeconomic mobility approach for the analysis of social inequalities in health.

Key words Health status disparities, Socioeconomic factors, Social mobility, Risk factors, Cardiovascular diseases
\end{abstract}

Resumo O presente estudo visa examinar a associação entre a posição socioeconômica (SEP) ao longo da vida e a frequência de hipertensão (HAS), com foco nos impactos da SEP durante a infância (SEPc), fase adulta (SEPa) e ao longo da vida. Foram analisados dados do Estudo de Coorte EpiFloripa ( $n=1.720,56 \%$ mulheres; $55 \%<=$ 30 anos). Determinou-se HAS pela média de duas mensurações de pressão arterial sistólica/diastólica, diagnóstico médico elou uso de medicação anti-hipertensiva ( $43 \%$ de hipertensos). As variáveis independentes foram: SEPa - nivel educacional dos participantes; SEPc - nível educacional dos pais; e mobilidade de SEP - trajetória socioeconômica de SEPc até SEPa. Cinco modelos de regressão logística foram ajustados para sexo, idade ou renda, e comparados entre si. Alta SEPa foi associada com redução de $37 \%$ no odds de HAS quando comparada à baixa SEPa. Alta SEP ao longo da vida foi associada com odds de HAS 34$37 \%$ menor quando comparada à baixa SEP ao longo da vida. Modelos de mobilidade explicaram mais da variância do desfecho do que os modelos de período sensivel. Os resultados encontrados reforçam a importância da educação para o risco de HAS e a relevância da mobilidade de SEP para as desigualdades sociais em saúde.

Palavras-chave Disparidades em saúde, Fatores socioeconômicos, Mobilidade social, Fatores de risco, Doenças cardiovasculares 


\section{Introduction}

Non-communicable chronic diseases (NCD) play a prominent role in the overall global mortality rate. Cardiovascular diseases (CVD) are among the most important NCDs, with approximately $46 \%$ of deaths by NCDs in 2012 being attributable to CVDs ${ }^{1}$. An important risk factor for CVD is systemic arterial hypertension $(\mathrm{SAH})^{2}$, which may be characterized by systolic (SBP) and diastolic blood pressures (DBP) equal to or greater than 130/80 (stage 1) and 140/90 $\mathrm{mmHg}$ (stage 2$)^{3}$.

Globally, NCDs and CVDs are unequally distributed. In particular, SAH is marked with persistent social inequalities. The unequal distribution of SAH has been observed in relation to different socioeconomic indicators, such as education, income, and occupation ${ }^{4-6}$, although education has shown the most consistent patterns of association with $\mathrm{SAH}^{4,7}$. In Brazil, the links between low education and increased rates of SAH have also been observed ${ }^{8,9}$.

There are a number of approaches to examining the links between socioeconomic position (SEP) and SAH. Some studies analyse SEP influences at particular stages of the life cycle, such as childhood (SEPc), youth (SEPy) and/ or adulthood (SEPa), independently $y^{4-6,10}$. Others analyse these influences across the life-course ${ }^{11-15}$. However, little is known about the relationship between SEP and SAH in low-middle income countries, such as Brazil, particularly how changes in SEP over the life-course might affect SAH. Understanding these relationships is particularly important given persistent social inequalities in these countries ${ }^{16}$ and the potential implications for public health interventions.

The present study aims to examine the links between SEP and SAH using a life-course approach with a particular focus on education in a sample of adults from a Southern Brazilian city. The study aimed to test the association between SEP across the life-course and the occurrence of $\mathrm{SAH}$, including an examination of both childhood and adult SEP, as well as SEP mobility.

\section{Socioeconomic position and hypertension}

SEP is characterized by socioeconomic factors that influence the position that individuals or groups hold in the social structure ${ }^{17}$. Educational level is a measure of SEP widely used in epidemiologic studies, given that it is frequently available for both sexes, is objective and stable over time, compared to, for example, occupation or income $e^{18,19}$. Education also represents the assets that a person possesses in relation to his/her formal knowledge ${ }^{17}$. Educational level can affect health outcomes, such as SAH, via multiple pathways. One way relates to the likelihood for people to adopt healthy behaviours ${ }^{20}$. For example, some studies indicate that people with higher education are better able to put in practice their knowledge and awareness of the disease ${ }^{21}$, more likely to keep their blood pressure (BP) under control ${ }^{20}$ and are better able to access health care services. Another pathway is through increased chances for those with higher education of being exposed to work and home environments that are more favourable from psychosocial, physical and economic perspectives ${ }^{22-24}$.

\section{Life-course approaches}

Life-course epidemiology is defined as the mechanisms by which social circumstances experienced during the life-course affect adult health and disease risk ${ }^{25,26}$. There are a number of life-course models that have been proposed to explain how harmful exposures throughout life could affect health, including SAH. These include: sensitive or critical period; accumulation of risk; pathways and social mobility models ${ }^{25,27-29}$.

The sensitive or critical period models consider the influence of exposures during an important period of human development (i.e., time window ${ }^{25,26}$. The accumulation of risk model considers that exposures in various time windows during the life-course result in accumulated influences on health ${ }^{29}$. The pathway model considers that one negative exposure leads to another negative exposure, so that these associations result in a chain of risks involving possible mediating factors ${ }^{26}$. This chain of risks develops throughout the life course, from childhood to the present moment, meaning that pathway models take into consideration exposures and mediators in a longitudinal perspective. And, finally, the social mobility models compare the socioeconomic patterns in different periods of life ${ }^{30}$, which can result in constant, upward or downward socioeconomic mobility ${ }^{28}$. The mobility models usually builds on a wide array of data, since they combine influences on health during childhood, adolescence and adulthood on exposures in adult life. 


\section{Life-course socioeconomic position models and hypertension}

A review of the literature indicated that the relationship between SEP and BP or SAH has been examined using all of the approaches mentioned above. The social mobility approach has been the most common ${ }^{11,12,14,29,31}$, although the accumulation of risk and/or pathway models were also tested in four studies ${ }^{13,15,29,31}$. The sensitive and critical period models were tested in four studies ${ }^{12,13,15,29}$. Of these life-course studies, one was conducted in South Africa ${ }^{14}$, three in Europe $^{12,15,31}$, and three in United States of America (US) ${ }^{11,13,29}$.

The most common SEP indicator used in these studies was occupation ${ }^{11,12,31}$. However, two studies also analysed education ${ }^{11,13}$, with one of them examining education at two different periods ${ }^{11}$. Three studies used a composite SEP measure, including income, education and occupation $^{13,15,29}$; and one study used a measure of household assets ${ }^{14}$. None of these studies analysed the mother's SEP independent of the father's SEP as an indicator of SEP in childhood.

The pathway models as well as the risk accumulation models found stronger evidence of the relationship between unfavourable SEP and $\mathrm{SAH}^{13,15,29,31}$ than the sensitive and critical period models, though the latter also found associations with $\mathrm{SAH}^{12,13,31}$. Among studies testing SEP mobility $^{11,12,14,29}$, only one did not find evidence of an association between SEP changes and SAH in African American adults in the US ${ }^{11}$. Effect modification by sex and race on the relationship between SEP and CVD risk was found in some studies $^{29,31}$. One study compared life-course and saturated models ${ }^{31}$ and found that life-course models could best describe the data.

While the current literature using life-course approaches indicates some links between SEP and $\mathrm{SAH}$, there are still significant knowledge gaps to be addressed. There is a dearth of studies in some countries, with some ethnic groups, and only three studies compared different life-course models ${ }^{13,14,31}$. In addition, no studies employing life-course approaches have examined the links between education and SAH in Brazil. The present study aims to fill these gaps by examining education and SAH in Brazil, and comparing two life-course approaches - the sensitive period and the social mobility models.

\section{Method}

\section{Participants}

Participant data from the EpiFloripa Cohort Study, which was carried out in the urban area of Florianopolis (Southern Brazil), were analysed $(\mathrm{n}=1,720)$. The sampling frame was by cluster in two stages: first, by a random draw of census tracts and second, by randomly selected households. The selected households were visited in person and their residents invited to participate. If after 4 visits, no one was found at home, the household was considered lost and was not part of the final sample, not even as missing data. Data from $85.3 \%$ of the initial sample calculated was collected ${ }^{32}$. Women who were over 3 months pregnant or who had given birth to a child in the six months prior to anthropometric and blood pressure measurements were included in the study $^{33}$. Further details of the study methodology have been previously described ${ }^{32}$.

The study commenced in 2009 with the first follow-up in 2012 ( $\mathrm{n}=1,222)$, and interviews took place at the participants' homes. Participants in the baseline were aged between 20 and 59 years. In 2009, BP levels were measured twice, using electronic pulse digital sphygmomanometer. The questionnaire included questions on health-related issues, participant's education, previous medical diagnosis of hypertension and use of anti-hypertensive medication. In the 2012 wave, parental education was also collected.

The Committee for Ethics in Research with Humans (CEPSH) of the Federal University of Santa Catarina approved the study protocol. All participants signed the Free and Informed Consent form after an explanation of the study objectives.

\section{Dependent variable}

Whenever the average of two measures of SBP and/or DBP were higher than or equal to $140 \mathrm{mmHg}$ and/or $90 \mathrm{mmHg}$, respectively, or when a previous medical diagnose of hypertension or the use of anti-hypertensive medication was reported, participants were classified as hypertensive $^{34,35}$. The participants should have at least one of these three condition to be classified as hypertensive. 


\section{Independent variables}

The participants' education was collected in 2009 , and was used as an indicator of SEPa, considering adulthood as a later sensitive period; the participants' parental education was collected in 2012, by means of a question asking their parents' educational level. This variable was used as an indicator of SEPc, considering childhood as an early sensitive period. Unlike previous studies $^{11,12,31}$, the present investigation analyses the association between hypertension and maternal and paternal SEPc independently, considering their independent influences on adult health ${ }^{36}$.

Education in Brazil is divided into three phases: primary (0-9 years), secondary (10-12 years) and higher education ( $>12$ years $)^{37}$. This classification was used to categorize the SEPa variable. However, the low and medium categories were combined (as low education) as the differentiation between these levels of education in Brazil is less marked than that between secondary and higher education ${ }^{38,39}$. Categorization of SEPc took into account the improvement of the level of education over time in Brazil ${ }^{40,41}$. We considered that older participants would have older parents, and that the median of years of parental education varied according to the age of the participants. Parents with education less than or equal to the median, according to age of the participants, were considered to have low education (low SEPc), while those with education above the median were classified as high education (high $\mathrm{SEPc}$ ).

The construction of two SEP mobility variables, one from the fathers' education and the other from the mothers' education, took into account four categories: constantly low, upward, downward and constantly high. These educational mobility categories considered changes in educational level between two generations, comparing the educational level achieved by the parents as well as the participants.

\section{Confounding and effect-modifying covariates}

The later life sensitive period and SEP mobility models were adjusted for sex and age (20-29, 30-39, 40-49, 50-63), which are frequently associated with $\mathrm{SAH}^{7,42,43}$ and education ${ }^{44}$. The early life sensitive period models were adjusted only for total household income, given that neither participant's sex nor age determine parental education. The later life sensitive period model was not adjusted for total household income, because this variable acts more as a mediator than as a confounder of the relationship between participants' education and hypertension. As tested in some studies ${ }^{29,31}$, sex and interviewer-classified race ("White" or 'Black or brown") were also analyzed as effect-modifiers of the relationship between socioeconomic status and CVD risk.

\section{Statistical analysis}

One later life sensitive period model, using the participants' education, was tested; two early life sensitive period models were tested, one using paternal and other using maternal SEPc; and two mobility models, one measuring the change in SEP from paternal SEPc to SEPa (paternal mobility model) and the other from maternal SEPc to SEPa (maternal mobility model). These five models were compared against each other. The later and early life sensitive period models were tested to estimate the association between SAH and SEP in both phases of life independently and to examine how they are related to adult SAH. The mobility models tested the mobility from SEPc to SEPa and their influences on SAH. This followed the hypothesis that both phases act jointly and that one phase could modify or cancel out the influence on health of the other phase. For example, these models were estimated to assess whether the health influences of a poor childhood on SAH could be mitigated or even reversed by a better socioeconomic condition in adulthood or vice-versa.

Statistical analyses were performed with Stata 14 software (Stata Corporation, College Station USA). Logistic regression models tested the association between SEP and SAH, taking into account the sampling weights and the complex sampling structure. For the selection of the final, more parsimonious models, a backward elimination procedure was used $(\mathrm{p}<0.05)$. We started with the full model, which included all independent variables (model F). Then, variables were removed from the full model, resulting in model F1. The fit of model $F$ was compared with the fit of model F1, such that the more parsimonious model could be selected whenever it was not statistically different from the full model. This procedure was repeated until the final and more parsimonious model was found. The Akaike's Information Criterion (AIC) and Bayesian Information Criterion (BIC) parameters were used to assess the fit of the models. The $\mathrm{R} 2$ coefficient values were also analysed to establish compari- 
sons among the five models. In addition, linear regression analysis was conducted to evaluate the consistency of the findings.

\section{Results}

Table 1 compares study respondents from the baseline in 2009 and the first follow-up, which took place in 2012. It shows that participants who were lost due to sample attrition in 2012 were not different from those interviewed at baseline in terms of sex, age, race, paternal and maternal SEP, and SEPa. There were negligible differences, though, with regards to total household income and SEPa, with participants in the 2012 follow-up study being more likely to report higher incomes and higher levels of education.

Table 2 describes the socio-demographic characteristics of the analytical sample (i.e., only those participants who were included in the statistical analyses), as well as the prevalence of hypertension according to these variables. Women (56.4\%), individuals between 20 and 29 years of age $(32.1 \%)$, whites $(91.4 \%)$ and those with high educational level $(50.6 \%)$ predominated in the sample, as well as individuals with consistently low educational mobility, both maternal (33.7\%) and paternal $(33.4 \%)$. Almost $44 \%$ of the sample was hypertensive. There was a higher prevalence of SAH among men (53.6\%), individuals over 50 years of age $(58.5 \%)$, 'Black' or 'Brown' participants (54.1\%), and those with low SEPa (48.7\%). There was no difference in the prevalence of hypertension by SEPc for either maternal or paternal SEP. In terms of social mobility, for those with consistently low or downward social mobility, the prevalence of hypertension was significantly higher than among those with consistently high or upward social mobility.

Table 3 shows the adjusted results for all sensitive SEP models. In the later sensitive model, even after adjustment for sex and age, high SEPa was associated with a $37 \%$ reduction in the odds of SAH compared to low SEPa. In paternal and maternal models, the odds observed for high SEPc was not significantly different from the low SEPc, despite adjustment for total household income. Table 4 shows that when analysing mobility between SEPc and SEPa adjusted for sex and age, a consistently high SEP over the life course was statistically associated with a reduction of the odds of SAH compared to constantly low SEP. Taken together, Tables 3 and 4 provide information on the fit statistics of each of the models we estimated. Fit indices showed greater support for the later sensitive model in relation to the parental education models. On the other hand, the SEP mobility models explained more of the outcome variance, with the maternal mobility model showing a slightly better performance when compared to the paternal mobility model.

Sex and race did not interact with the main exposures of interest (results not shown in tables). Additional linear analyses, not shown in the paper but available from the authors upon request, were consistent with the results from logistic models.

\section{Discussion}

The present study examined the impact of education on hypertension in a sample of adults in the South of Brazil drawing from a life-course perspective. It found a statistically significant association between SEPa and SAH, but not between SEPc and SAH. SEP mobility was associated with SAH only when high SEP was constant from childhood to adulthood, compared to those consistently low.

The high prevalence of SAH observed in the sample $(42.7 \%)$ was more than twice the prevalence observed by Brazilian population studies, such as the National Health Survey (PNS), 2013 (21.4\%), and the Vigitel, $2015(22.2 \%)^{45,46}$. However, these studies included only medical diagnosis of SAH reported by the participants, whereas the present study also included the use of antihypertensive drugs (5.2\%) and BP average measured in two moments, which may have contributed to the greater number of individuals classified as hypertensive.

Males were associated with a higher prevalence of SAH in the present study, as observed by other authors ${ }^{47,48}$, though some studies have found more mixed results ${ }^{11,12,49}$. The prevalence of SAH was higher among 'Browns' or 'Blacks', corroborating previously observed results in relation to racial categories ${ }^{50}$ as an indicator of social and racial inequalities ${ }^{51,52}$, though previously Ordunez et al. ${ }^{48}$ found no racial differences in their Cuban sample.

The results of the present study lend support to an inverse relationship between SEPa and $\mathrm{SAH}$, which has been observed in other studies $^{12,13,49,53,54}$. As noted, education may influence BP through the adoption of specific behaviours, access to health care, awareness of the illness risks ${ }^{5,20,21}$, as well as the stress and effort 
Table 1. Comparison between original and analytical sample. Florianópolis, Southern of Brazil, 2009.

\begin{tabular}{|c|c|c|c|c|c|}
\hline \multirow[t]{2}{*}{ Variables } & \multicolumn{2}{|c|}{$\begin{array}{c}2009 \text { sample }(\mathrm{N}= \\
1720)\end{array}$} & \multicolumn{2}{|c|}{$\begin{array}{c}\text { Analytical sample (N } \\
=926)\end{array}$} & \multirow[t]{2}{*}{$\begin{array}{c}\text { p-value } \\
2009 \times \text { nomiss }\end{array}$} \\
\hline & $\mathbf{N}$ & $\%$ & $\mathbf{N}$ & $\%$ & \\
\hline \multicolumn{6}{|l|}{ Hypertension } \\
\hline No & 939 & 55.7 & 530 & 57.3 & 0.457 \\
\hline Yes & 746 & 44.3 & 396 & 42.7 & \\
\hline \multicolumn{6}{|l|}{ Sex } \\
\hline Male & 765 & 44.5 & 403 & 43.6 & 0.637 \\
\hline Female & 955 & 55.5 & 523 & 56.4 & \\
\hline \multicolumn{6}{|l|}{ Age } \\
\hline 20-29 & 562 & 32.7 & 299 & 32.3 & 0.349 \\
\hline $30-29$ & 388 & 22.6 & 213 & 23.0 & \\
\hline $40-49$ & 433 & 25.2 & 256 & 27.7 & \\
\hline $50+$ & 336 & 19.5 & 159 & 17.2 & \\
\hline \multicolumn{6}{|l|}{ Race } \\
\hline White & 1539 & 89.5 & 846 & 91.4 & 0.121 \\
\hline Brown and black & 181 & 10.5 & 80 & 8.6 & \\
\hline \multicolumn{6}{|l|}{ Total household income } \\
\hline $1^{\circ}$ tertile & 640 & 38.0 & 274 & 29.6 & $<0.001$ \\
\hline $2^{\circ}$ tertile & 511 & 30.3 & 299 & 32.3 & \\
\hline $3^{\circ}$ tertile & 535 & 31.8 & 352 & 38.1 & \\
\hline \multicolumn{6}{|l|}{ Socioeconomic Position - SEP } \\
\hline \multicolumn{6}{|l|}{ Adulthood - SEPa } \\
\hline Low $(<=12$ years of school $)$ & 1017 & 59.3 & 457 & 49.4 & 0.001 \\
\hline High $(>=13$ years of school $)$ & 699 & 40.7 & 469 & 50.6 & \\
\hline \multicolumn{6}{|l|}{ Childhood - SEPc } \\
\hline \multicolumn{6}{|l|}{ Father } \\
\hline Low $(<=$ median years of school $)$ & 560 & 54.8 & 493 & 53.2 & 0.507 \\
\hline High (> median years of school) & 463 & 45.2 & 433 & 46.8 & \\
\hline \multicolumn{6}{|l|}{ Mother } \\
\hline Low $(<=$ median years of school $)$ & 582 & 54.5 & 485 & 52.4 & 0.333 \\
\hline High (> median years of school) & 485 & 45.5 & 441 & 47.6 & \\
\hline \multicolumn{6}{|l|}{ Mobility } \\
\hline \multicolumn{6}{|l|}{ Father } \\
\hline Low (SEPc low $\rightarrow$ SEPa low) & 368 & 36.1 & 309 & 33.4 & 0.614 \\
\hline Downward (SEPc high $\rightarrow$ SEPa low) & 164 & 16.0 & 148 & 16.0 & \\
\hline Upward (SEPc low $\rightarrow$ SEPa high) & 191 & 18.8 & 184 & 19.9 & \\
\hline High (SEPc high $\rightarrow$ SEPa high) & 297 & 29.1 & 285 & 30.7 & \\
\hline \multicolumn{6}{|l|}{ Mother } \\
\hline Low (SEPc low $\rightarrow$ SEPa low) & 394 & 37.0 & 312 & 33.7 & 0.361 \\
\hline Downward (SEPc high $\rightarrow$ SEPa low) & 173 & 16.3 & 145 & 15.7 & \\
\hline Upward (SEPc low $\rightarrow$ SEPa high) & 187 & 17.6 & 173 & 18.7 & \\
\hline High (SEPc high $\rightarrow$ SEPa high) & 310 & 29.1 & 295 & 31.9 & \\
\hline
\end{tabular}

* Pearson Chi-squared test.

related to occupation and income $e^{5,54}$. In this context, a study using the same EpiFloripa study data found that the prevalence of SAH among individuals with manual occupation was higher $(49.0 \%)$ than between those with non-manual occupation $(36.8 \%)^{55}$.
Regarding SEPc, there was no association between parental education, for either maternal or paternal education, and adult SAH in the present study. Previous studies have found significant associations between parental income and $\mathrm{SAH}^{12,13}$ and a composite measure of parental SEP that 
Table 2. Distribution of sample, according to socio demographic characteristics and hypertension, Florianópolis, Southern of Brazil, 2009.

\begin{tabular}{|c|c|c|c|c|c|}
\hline \multirow{2}{*}{ Variables } & \multicolumn{2}{|c|}{ Total $(926)^{\star}$} & \multicolumn{3}{|c|}{ Hypertension } \\
\hline & $\mathbf{n}$ & $\%$ & $\%$ & IC95\% & p-Value ${ }^{* *}$ \\
\hline \multicolumn{6}{|l|}{ Sex } \\
\hline Male & 403 & 43.6 & 53.6 & $47.9 ; 59.3$ & $<0.001$ \\
\hline Female & 523 & 56.4 & 34.3 & $29.7 ; 39.3$ & \\
\hline \multicolumn{6}{|l|}{ Age } \\
\hline 20-29 & 298 & 32.1 & 32.8 & $27.1 ; 39.1$ & $<0.001$ \\
\hline $30-29$ & 213 & 23.0 & 38.5 & $31.4 ; 46.2$ & \\
\hline $40-49$ & 256 & 27.7 & 48.0 & $42.5 ; 53.6$ & \\
\hline $50-63$ & 159 & 17.2 & 58.5 & $51.1 ; 65.6$ & \\
\hline \multicolumn{6}{|l|}{ Race } \\
\hline White & 846 & 91.4 & 41.7 & $37.5 ; 46.0$ & 0.064 \\
\hline Brown and black & 80 & 8.6 & 54.1 & $41.1 ; 66.6$ & \\
\hline \multicolumn{6}{|l|}{ Total household income } \\
\hline $1^{\circ}$ tertile & 274 & 29.6 & 42.2 & $35.6 ; 49.1$ & 0.066 \\
\hline $2^{\circ}$ tertile & 299 & 32.3 & 49.3 & $40.8 ; 57.8$ & \\
\hline $3^{\circ}$ tertile & 352 & 38.1 & 37.6 & $32.2 ; 43.4$ & \\
\hline \multicolumn{6}{|l|}{ Education in adulthood - $\mathrm{SEPa}^{\phi}$} \\
\hline Low $(<=12$ years of school) & 457 & 49.4 & 48.7 & $46.6 ; 56.0$ & $<0.001$ \\
\hline High $(>=13$ years of school) & 469 & 50.6 & 36.9 & $31.8 ; 42.4$ & \\
\hline \multicolumn{6}{|l|}{ Education in childhood - SEPc ${ }^{x}$} \\
\hline \multicolumn{6}{|l|}{ Father's education } \\
\hline Low $(<=$ median years of school $)$ & 493 & 53.2 & 42.5 & $37.6 ; 47.6$ & 0.888 \\
\hline High (> median years of school) & 433 & 46.8 & 43.0 & $37.7 ; 48.5$ & \\
\hline \multicolumn{6}{|l|}{ Mother's education } \\
\hline Low $(<=$ median years of school $)$ & 486 & 52.4 & 43.0 & $37.9 ; 48.3$ & 0.863 \\
\hline High (> median years of school) & 440 & 47.6 & 42.5 & $37.7 ; 47.4$ & \\
\hline \multicolumn{6}{|l|}{ Educational Mobility } \\
\hline \multicolumn{6}{|l|}{ Father } \\
\hline Low $($ low $\rightarrow$ low $)$ & 309 & 33.4 & 44.7 & $39.2 ; 50.4$ & $<0.001$ \\
\hline Downward (high $\rightarrow$ low) & 148 & 16.0 & 57.1 & $48.4 ; 65.5$ & \\
\hline Upward (low $\rightarrow$ high) & 184 & 19.9 & 38.9 & $30.9 ; 47.5$ & \\
\hline High (high $\rightarrow$ high) & 285 & 30.7 & 35.6 & $30.1 ; 41.6$ & \\
\hline \multicolumn{6}{|l|}{ Mother } \\
\hline Low $($ low $\rightarrow$ low $)$ & 312 & 33.7 & 44.8 & $38.9 ; 50.8$ & $<0.001$ \\
\hline Downward (high $\rightarrow$ low) & 145 & 15.7 & 57.2 & $49.2 ; 64.7$ & \\
\hline Upward (low $\rightarrow$ high) & 173 & 18.7 & 39.8 & $32.0 ; 48.1$ & \\
\hline High (high $\rightarrow$ high $)$ & 295 & 31.9 & 35.2 & $29.9 ; 41.0$ & \\
\hline
\end{tabular}

${ }^{*}$ Analitical sample with participants without missing data. ${ }^{*}$ Pearson Chi-squared test. $\phi$ SEPa: Socioeconomic position in adult. XSEPc: Socioeconomic position in childhood.

included parental education ${ }^{15}$. While these studies used different measures, it may also be that the retrospective measures of parental education collected may have contributed to the lack of significant results found in the present study.

Regarding SEP mobility, it was observed that only consistently high SEP throughout life was associated with reduced odds of SAH compared to those individuals who remained in the lowest
SEP throughout life. These results corroborate the findings of a study with African American men in the United States ${ }^{13}$. A study in Sweden observed a reduction in the odds of SAH for individuals with upward social mobility ${ }^{12}$, but another study (in the United States) did not find any association ${ }^{11}$. The results found here may reflect a persistence in SEP in Brazil, especially at social extremes ${ }^{16}$, and highlights the importance 
Table 3. Comparison of three sensitive logistic regression models to predict hypertension, Florianópolis, Southern of Brazil, 2009.

\begin{tabular}{|c|c|c|c|c|c|c|c|c|c|}
\hline \multirow{3}{*}{ Variables } & \multicolumn{9}{|c|}{ Hypertension } \\
\hline & \multicolumn{3}{|c|}{$\begin{array}{c}\text { Participant education model } \\
\phi \phi\end{array}$} & \multicolumn{3}{|c|}{ Paternal education model ${ }^{\star}$} & \multicolumn{3}{|c|}{ Maternal education model ${ }^{\star}$} \\
\hline & OR & CI95\% & p-val. & OR & CI95\% & p-val. & OR & CI95\% & p-val. \\
\hline \multicolumn{10}{|l|}{ Sex } \\
\hline Male & 1.00 & $(-)$ & - & - & - & - & - & - & - \\
\hline Female & 0.43 & $0.32 ; 0.57$ & $<0.001$ & - & - & - & - & - & - \\
\hline \multicolumn{10}{|l|}{ Age } \\
\hline $20-29$ & 1.00 & $(-)$ & - & - & - & - & - & - & - \\
\hline $30-39$ & 1.36 & $0.91 ; 2.04$ & 0.136 & - & - & - & - & - & - \\
\hline $40-49$ & 2.08 & $1.43 ; 3.02$ & $<0.001$ & - & - & - & - & - & - \\
\hline $50-63$ & 2.95 & $1.89 ; 4.61$ & $<0.001$ & - & - & - & - & - & - \\
\hline \multicolumn{10}{|l|}{$\mathrm{SEPa}^{\star}$} \\
\hline Low & 1.00 & $(-)$ & - & - & - & - & - & - & - \\
\hline High & 0.63 & $0.47 ; 0.84$ & 0.001 & - & - & - & - & - & - \\
\hline \multicolumn{10}{|l|}{ SEPcFather ${ }^{\star}$} \\
\hline Low & - & - & - & 1.00 & $(-)$ & - & - & - & - \\
\hline High & - & - & - & 1.09 & $0.82 ; 1.45$ & 0.564 & - & - & - \\
\hline \multicolumn{10}{|l|}{ SEPcMoth ${ }^{*}$} \\
\hline Low & - & - & - & - & - & - & 1.00 & $(-)$ & - \\
\hline High & - & - & - & - & - & - & 1.04 & $0.78 ; 1.39$ & 0.775 \\
\hline \multicolumn{10}{|l|}{ Income } \\
\hline $1^{\circ}$ tertile & - & - & - & 1.00 & $(-)$ & - & 1.00 & $(-)$ & - \\
\hline $2^{\circ}$ tertile & - & - & - & 1.32 & $0.93 ; 1.86$ & 0.119 & 1.32 & $0.94 ; 1.87$ & 0.11 \\
\hline $3^{\circ}$ tertile & - & - & - & 0.80 & $0.56 ; 1.14$ & 0.219 & 0.81 & $0.57 ; 1.16$ & 0.253 \\
\hline R2 Adj & & 0.0645 & & & 0.0075 & & & 0.0072 & \\
\hline AIC & & 131.506 & & & 139.518 & & & 139.549 & \\
\hline BIC & & 115492.74 & & & 122897.36 & & & 122926.14 & \\
\hline
\end{tabular}

${ }^{\star}$ SEP. Socioeconomic Position. SEPa: Socioeconomic Position in Adulthood. SEPc: Socioeconomic Position in Childhood. ${ }^{\star} \phi$ SEPa: Low ( $<=12$ years of school); High $\left(>=13\right.$ years of school) ${ }^{* \star} \operatorname{SEPc}$ (Father and mother). Low $(<=$ median years of school); High ( $>$ median years of school). Participant education model. later life sensitive period model; Paternal education model. early life sensitive period model (Father); Maternal education model. early life sensitive period model (Mother).

of considering country context when examining SEP mobility and health outcomes. Mobility in other measures of SEP are also important to examine.

Participant education explained more of the occurrence of SAH than parental education, which may be related to short-term response from BP to various environmental stressors, including those related to work and income ${ }^{56}$. When analysing the mobility from SEPc to SEPa, educational mobility from mother explained more of the SAH in the participants than educational mobility from father, suggesting a greater relevance of maternal education for the impact of SEP mobility on SAH over the life-course. As mothers still tend to spend more time with their children than fa- thers, their influence on children's knowledge and behaviours may be greater ${ }^{57}$.

Sex did not moderate the relation between education and SAH, despite other studies showing that sex might be an effect modifier $^{57}$; the same was observed for race, in contrast to what was found by other studies ${ }^{29,31,58}$. The binary classification of the education variable may have obscured the interaction between racial categories and the potential impact of more subtle educational mobility ${ }^{59}$.

\section{Strengths and limitations}

The present study makes a significant contribution to understanding the impact of changes 
Table 4. Comparison of two mobility logistic regression models to predict hypertension, Florianópolis, Southern of Brazil, 2009.

\begin{tabular}{|c|c|c|c|c|c|c|}
\hline \multirow{3}{*}{ Variables } & \multicolumn{6}{|c|}{ Hypertension } \\
\hline & \multicolumn{3}{|c|}{ Paternal mobility model } & \multicolumn{3}{|c|}{ Maternal mobility model } \\
\hline & OR & CI95\% & p-val. & OR & CI95\% & p-val. \\
\hline \multicolumn{7}{|l|}{ Sex } \\
\hline Male & 1.00 & $(-)$ & - & 1.00 & $(-)$ & - \\
\hline Female & 0.43 & $0.32 ; 0.58$ & $<0.001$ & 0.43 & $0.32 ; 0.57$ & $<0.001$ \\
\hline \multicolumn{7}{|l|}{ Age } \\
\hline 20-29 & 1.00 & $(-)$ & - & 1.00 & $(-)$ & - \\
\hline $30-39$ & 1.37 & $0.91 ; 2.06$ & 0.131 & 1.36 & $0.90 ; 2.04$ & 0.142 \\
\hline $40-49$ & 2.07 & $1.42 ; 3.02$ & $<0.001$ & 2.07 & $1.42 ; 3.01$ & $<0.001$ \\
\hline $50-63$ & 2.89 & $1.85 ; 4.51$ & $<0.001$ & 2.85 & $1.82 ; 4.45$ & $<0.001$ \\
\hline \multicolumn{7}{|l|}{ Mobil.Father } \\
\hline Low & 1.00 & $(-)$ & - & - & - & - \\
\hline Downward & 1.47 & $0.96 ; 2.25$ & 0.076 & - & - & - \\
\hline Upward & 0.80 & $0.53 ; 1.20$ & 0.281 & - & - & - \\
\hline High & 0.66 & $0.46 ; 0.95$ & 0.024 & - & - & - \\
\hline \multicolumn{7}{|l|}{ Mobil.Mother } \\
\hline Low & - & - & - & 1.00 & $(-)$ & - \\
\hline Downward & - & - & - & 1.40 & $0.91 ; 2.14$ & 0.122 \\
\hline Upward & - & - & - & 0.83 & $0.55 ; 1.25$ & 0.378 \\
\hline High & - & - & - & 0.63 & $0.44 ; 0.90$ & 0.012 \\
\hline R2 Adj & & 0.0679 & & & 0.068 & \\
\hline AIC & & 131.03 & & & 131.02 & \\
\hline BIC & & 115061.64 & & & 115051.81 & \\
\hline
\end{tabular}

Paternal mobility model. SEP mobility model (Father); Maternal mobility model. SEP mobility model (Mother).

in SEP over the life course on the occurrence of SAH in the Brazilian population. The study used an objective measure of $\mathrm{BP}$ as well as previous medical diagnosis and the use of antihypertensive drugs to classify hypertension. However, there are a number of study limitations to note.

Although stability over time is a positive aspect of education as a measure of SEP, it also can mean more subtle or changeable aspects of social mobility are not captured, such as ownership of goods. In addition, parental education was measured retrospectively. Other measures of SEP and other influences, such as neighborhood and family structure, should be considered in the analysis of how SEP throughout life affects SAH in adulthood, especially in poorer countries such as Brazil.

The models tested in this study explained a small proportion of the outcome variance, possibly because some risk factors, including smoking and physical activity, were not considered. However, the model comparisons may assist future research in determining the best approach to analyse socioeconomic inequalities in SAH.
Losses and refusals to take part in the study rates were high in the follow-up study, when parental education was collected. Despite this, the sample in both waves were similar according to a number of socioeconomic and demographic characteristics.

\section{Conclusion}

The results observed in the present study reinforce the importance of education for SAH risk and the relevance of a socioeconomic mobility approach in the analysis of social inequalities in health. The mobility from education in childhood to adulthood emphasizes the potentially intractable nature of disadvantage as upward SEP mobility did not significantly reduce the risk of SAH. This highlights the important social and public health imperatives of addressing social disadvantage at its roots in childhood. 


\section{Collaborations}

W Nishida contributed to collecting, analyzing and interpreting the data, and drafting the manuscript. A Ziersch followed the development of the project, interpreted the data, supervised and revised the final manuscript. C Zanelatto, KJP Wagner and AF Boing followed the development and revised the manuscript. JLD Bastos was responsible for research coordination, supervision and revision of the final analysis and manuscript.

\section{References}

1. World Health Organization (WHO). Global status report on noncommunicable diseases 2014. Attaining the nine global noncommunicable diseases targets a shared responsibility. Geneva: WHO; 2014.

2. Redon J, Tellez-Plaza M, Orozco-Beltran D, Gil-Guillen V, Fernandez SP, Navarro-Perez J, Pallares V, Valls F, Fernandez A, Perez-Navarro AM, Sanchis C, Dominguez-Lucas A, Sanz G, Martin-Moreno JM, ESCARVAL Study Group. Impact of hypertension on mortality and cardiovascular disease burden in patients with cardiovascular risk factors from a general practice setting: the ESCARVAL-risk study. J Hypertens 2016; 34(6):1075-1083.

3. Whelton PK, Carey RM, Aronow WS, Casey Junior DE, Collins KJ, Himmelfarb CD, DePalma SM, Gidding S, Jamerson KA, Jones DW, MacLaughlin EJ, Muntner P, Ovbiagele B, Smith Junior SC, Spencer CC, Stafford RS, Taler SJ, Thomas RJ, Williams Sr KA, Williamson JD, Wright Junior JT. 2017 ACC/AHA/ AAPA/ABC/ACPM/AGS/APhA/ASH/ASPC/NMA/ PCNA Guideline for the Prevention, Detection, Evaluation, and Management of High Blood Pressure in Adults: Executive Summary: A Report of the American College of Cardiology/American Heart Association Task Force on Clinical Practice Guidelines. $\mathrm{Hy}$ pertension 2018; 71:1269-1324.

4. Conen D, Glynn RJ, Ridker PM, Buring JE, Albert MA. Socioeconomic status, blood pressure progression, and incident hypertension in a prospective cohort of female health professionals. Eur Heart J 2009; 30(11):1378-1384.

5. Grotto I, Huerta M, Sharabi Y. Hypertension and socioeconomic status. Curr Opin Cardiol 2008; 23(4):335-339.

6. Brummett BH, Babyak MA, Siegler IC, Shanahan M, Harris KM, Elder GH, Williams RB. Systolic blood pressure, socioeconomic status, and biobehavioral risk factors in a nationally representative US young adult sample. Hypertension 2011; 58(2):161-166.

7. Winkleby MA, Jatulis DE, Frank E, Fortmann SP. Socioeconomic status and health: how education, income, and occupation contribute to risk factors for cardiovascular disease. Am J Public Health 1992; 82(6):816-820.

8. Malta DC, Bernal RT, Souza MF, Szwarcwald CL, Lima MG, Barros MB. Social inequalities in the prevalence of self-reported chronic non-communicable diseases in Brazil: national health survey 2013. Int J Equity Health 2016; 15(1):153.

9. Instituto Brasileiro de Geografia e Estatística (IBGE). Pesquisa Nacional de Saúde - 2013. Percepção do estado de saúde, estilos de vida e doenças crônicas. Brasil, Grandes Regiões e Unidades da Federação. Rio de Janeiro: IBGE, Fiocruz; 2013.

10. Galobardes B, Smith GD, Lynch JW. Systematic review of the influence of childhood socioeconomic circumstances on risk for cardiovascular disease in adulthood. Ann Epidemiol 2006; 16(2):91-104.

11. Broman CL. Social-Mobility and Hypertension among Blacks. J Behav Med 1989; 12(2):123-134. 
12. Hogberg L, Cnattingius S, Lundholm C, Sparen P, Iliadou AN. Intergenerational social mobility and the risk of hypertension. J Epidemiol Community Health 2012; 66:6

13. James SA, Van Hoewyk J, Belli RF, Strogatz DS, Williams DR, Raghunathan TE. Life-course socioeconomic position and hypertension in African American men: The Pitt County Study. Am J Public Health 2006; 96(5):812-817.

14. Kagura J, Adair LS, Pisa PT, Griffiths PL, Pettifor JM, Norris SA. Association of socioeconomic status change between infancy and adolescence, and blood pressure, in South African young adults: Birth to Twenty Cohort. BMJ Open 2016; 6:3.

15. Kivimaki M, Lawlor DA, Smith GD, Keltikangas-Jarvinen L, Elovainio M, Vahtera J, Pulkki-Råback L, Taittonen L, Viikari JSA, Raitakari OT. Early socioeconomic position and blood pressure in childhood and adulthood - The Cardiovascular Risk in Young Finns Study. Hypertension 2006; 47(1):39-44.

16. Mahlmeister R, Ferreira SG, Veloso F, Filho NM, Komatsu BK. Revisitando a Mobilidade Intergeracional de Educação no Brasil. São Paulo: Insper; 2017.

17. Galobardes B, Shaw M, Lawlor DA, Lynch JW, Smith GD. Indicators of socioeconomic position (part 1). J Epidemiol Community Health 2006; 60(1):7-12.

18. Krieger N, Williams DR, Moss NE. Measuring social class in US public health research: concepts, methodologies, and guidelines. Annu Rev Public Health 1997; 18:341-378.

19. Lynch J, Kaplan G. Socioeconomic position. In: Berckman LF, Kawashi I, Glymour M, editors. Social Epidemiology. New York: Oxford University Press; 2000. p. 13-35.

20. Cutler DM, Lleras-Muney A. Understanding differences in health behaviors by education. $J$ Health Econ 2010; 29(1):1-28.

21. Tedesco MA, Di Salvo G, Caputo S, Natale F, Ratti G, Iarussi D, Iacono A. Educational level and hypertension: how socioeconomic differences condition health care. J Hum Hypertens 2001; 15(10):727-731.

22. Chaix B, Bean K, Leal C, Thomas F, Havard S, Evans D, Jégo B, Pannier B. Individual/neighborhood social factors and blood pressure in the RECORD Cohort Study: which risk factors explain the associations? $\mathrm{Hy}$ pertension 2010; 55(3):769-775.

23. Zimmerman E, Woolf SH. Understanding the relationship between education and health. Discussion Paper. Washington: Institute of Medicine; 2014.

24. Kaikkonen R, Harkanen T, Rahkonen O, Gould R, Koskinen S. Explaining educational differences in sickness absence: a population-based follow-up study. Scand J Work Env Hea 2015; 41(4):338-346.

25. Ben-Shlomo Y, Cooper R, Kuh D. The last two decades of life course epidemiology, and its relevance for research on ageing. Int J Epidemiol 2016; 45(4):973-988.

26. Kuh D, Ben-Shlomo Y, Lynch J, Hallqvist J, Power C. Life course epidemiology. I Epidemiol Community Health 2003; 57(10):778-783.
27. Ben-Shlomo Y, Kuh D. A life course approach to chronic disease epidemiology: conceptual models, empirical challenges and interdisciplinary perspectives. Int J Epidemiol 2002; 31(2):285-293.

28. Pollitt RA, Rose KM, Kaufman JS. Evaluating the evidence for models of life course socioeconomic factors and cardiovascular outcomes: a systematic review. BMC Public Health 2005; 5:7.

29. Walsemann KM, Goosby BJ, Farr D. Life course SES and cardiovascular risk: Heterogeneity across race/ ethnicity and gender. Soc Sci Med 2016; 152:147-155.

30. Hallqvist J, Lynch J, Bartley M, Lang T, Blane D. Can we disentangle life course processes of accumulation, critical period and social mobility? An analysis of disadvantaged socio-economic positions and myocardial infarction in the Stockholm Heart Epidemiology Program. Soc Sci Med 2004; 58(8):1555-1562.

31. Murray ET, Mishra GD, Kuh D, Guralnik J, Black S, Hardy R. Life course models of socioeconomic position and cardiovascular risk factors: 1946 birth cohort. Ann Epidemiol 2011; 21(8):589-597.

32. Boing AC, Peres KG, Boing AF, Hallal PC, Silva NN, Peres MA. EpiFloripa Health Survey: the methodological and operational aspects behind the scenes. Brazilian journal of epidemiology 2014; 17(1):147-162.

33. Bernardo CO. Associação entre experiências discriminatórias e ganho de peso, circunferência da cintura e indice de massa corporal em adultos de Florianópolis, SC: Estudo de base populacional. Florianópolis: Federal University of Santa Catarina; 2015.

34. American Heart Association (AHA, ASA). Understanding and Managing High Blood Pressure. Dallas: AHA, ASA; 2016.

35. Malachias MVB, Plavnik FL, Machado CA, Malta D, Scala LCN, Fuchs S. (7a Diretriz Brasileira de Hipertensão Arterial: Capítulo 1 - Conceituação, Epidemiologia e Prevenção Primária. Arq. Bras. Cardiol. 2016; 107(3 Suppl. 3):1-6.

36. Semba RD, de Pee S, Sun K, Sari M, Akhter N, Bloem MW. Effect of parental formal education on risk of child stunting in Indonesia and Bangladesh: a cross-sectional study. Lancet 2008; 371(9609):322328.

37. Brasil. Saiba como é a divisão do sistema de educação brasileiro. Brasília: Agência Brasil; 2014.

38. Karademas EC, Kalantzi-Azizi A. The stress process, self-efficacy expectations, and psychological health. Pers Indiv Differ 2004; 37(5):1033-1043.

39. Fromme K, Corbin WR, Kruse MI. Behavioral risks during the transition from high school to college. Dev Psychol 2008; 44(5):1497-1504.

40. Organisation for Economic Co-operation and Development (OECD). Education at a Glance 2011: OECD Indicators. Paris: OECD; 2011.

41. Helene O. Evolução da escolaridade esperada no Brasil ao longo do século XX. Educação e Pesquisa 2012; 38(1):197-215.

42. Cicconetti P, Cacciafesta M, Migliori M, Di Gioacchino CF, Vetta F, Chiarotti F, Marigliano V. Influence of sex and age on blood pressure variability. Arch Gerontol Geriatr 2000; 30(3):225-236. 
43. Daugherty SL, Masoudi FA, Ellis JL, Ho PM, Schmittdiel JA, Tavel HM, Selby JV, O'Connor PJ, Margolis KL, Magid DJ. Age-dependent gender differences in hypertension management. J Hypertens 2011; 29(5):1005-1011.

44. Buchmann C, DiPrete TA, McDaniel A. Gender inequalities in education. Annu Rev Sociol 2008; 34:319337.

45. Instituto Brasileiro de Geografia e Estatística (IBGE), Fiocruz. Percepção do estado de saúde,estilos de vida e doenças crônicas - Brasil, Grandes Regiões e Unidades de Federação. Rio de Janeiro: IBGE, Fiocruz; 2014.

46. Brasil. Ministério da Saúde (MS). Vigitel Brasil 2015. Vigilância de fatores de risco e proteção para doenças crônicas por inquérito telefônico. Brasília: MS; 2016.

47. Alves RF, Faerstein E. Educational inequalities in hypertension: complex patterns in intersections with gender and race in Brazil. Int J Equity Health 2016; 15(1):146.

48. Ordunez P, Kaufman JS, Benet M, Morejon A, Silva LC, Shoham DA, Cooper RS. Blacks and Whites in the Cuba have equal prevalence of hypertension: confirmation from a new population survey. BMC Public Health. 2013; 13:169.

49. Beltran-Sanchez H, Crimmins EM, Teruel GM, Thomas D. Links between childhood and adult social circumstances and obesity and hypertension in the Mexican population. J Aging Health 2011; 23(7):11411165.

50. Cooper RS, Forrester TE, Plange-Rhule J, Bovet P, Lambert EV, Dugas LR, Cargill KE, Durazo-Arvizu RA, Shoham DA, Tong L, Cao G, Luke A. Elevated hypertension risk for African-origin populations in biracial societies: modeling the Epidemiologic Transition Study. J Hypertens 2015; 33(3):473-480; discussion 80-1.

51. Kaufman JS, Cooper RS. Commentary: Considerations for Use of Racial/Ethnic Classification in Etiologic Research. Am J Epidemiol 2001; 154(4):291-298.

52. Williams DR, Mohammed SA, Leavell J, Collins C. Race, Socioeconomic Status and Health: Complexities, Ongoing Challenges and Research Opportunities. Ann N Y Acad Sci 2010; 1186:69-101.
53. Christiani Y, Byles JE, Tavener M, Dugdale P. Assessing socioeconomic inequalities of hypertension among women in Indonesia's major cities. J Hum Hypertens 2015; 29(11):683-688.

54. Leng B, Jin YN, Li G, Chen L, Jin N. Socioeconomic status and hypertension: a meta-analysis. J Hypertens 2015; 33(2):221-229.

55. Silva DAS, Petroski EL, Peres MA. Prehypertension and hypertension among adults in a metropolitan area in Southern Brazil: population-based study. Rev Saude Publica 2012; 46(6):988-998.

56. Mariammal T, Jaisheeba AA, Sornaraj R. Work influenced occupational stress and cardiovascular risk among teachers and office workers. J Chem Pharm Res 2012; 4(3):1807-1811.

57. Janicki-Deverts D, Cohen S, Matthews KA, Jacobs Junior DR. Sex differences in the association of childhood socioeconomic status with adult blood pressure change: the CARDIA study. Psychosom Med 2012; 74(7):728-735.

58. Lehman BJ, Taylor SE, Kiefe CI, Seeman TE. Relationship of early life stress and psychological functioning to blood pressure in the CARDIA study. Health Psychol 2009; 28(3):338-346.

59. Instituto Brasileiro de Geografia e Estatística (IBGE). Características etnico-raciais da população. Rio de Janeiro: IBGE; 2013.

Article submitted 19/04/2018

Approved 12/11/2018

Final version submitted 14/11/2018 